\title{
Impact of a focused review course in cardiovascular and thoracic surgery on test performance
}

\author{
John R. Doty, MD, ${ }^{\mathrm{a}}$ Michael Nguyen, MS, ${ }^{\mathrm{b}}$ Richard J. Snyder, BS, ${ }^{\mathrm{b}}$ Ulysse G. McCann, MD, ${ }^{\mathrm{a}}$ and \\ Donald B. Doty, MD
}

\section{ABSTRACT}

Background: The Core Curriculum Review Course in Cardiovascular and Thoracic Surgery is a 4-day educational program consisting of 77 didactic lectures that provide a comprehensive review of the material required for surgeons preparing for the American Board of Thoracic Surgery competency written examination. The lectures are supplemented with a written syllabus and interactive audience participation system. We sought to determine whether participation in this course could improve participants' performance on a cardiothoracic subject-based test.

Methods: Sixty-five participants attended the 2018 course. Before beginning the course lectures, a multiple-choice pretest consisting of 77 questions was administered via mobile application to gauge the participants' baseline knowledge. A second multiple-choice posttest was made available beginning 7 weeks after the course, also by mobile application.

Results: Twenty-nine participants completed both the pretest and the posttest. The median pretest score was $47 \%$ (36 of 77 correct answers). The median posttest score was $61 \%$ (47 of 77 correct answers), representing an increase of $14 \%$. The Wilcoxon signed-rank test indicated a significant difference between the pretest and posttest scores $(z=-4.36 ; P=.00)$. Overall, 25 participants $(86 \%)$ improved their posttest score.

Conclusions: The core curriculum review course was successful in improving participants' performance on the course tests, indicating that the participants' fund of knowledge was likely increased by attendance at the program. Additional strategies should be considered to address particular areas of study both for individual participants and for residents currently in training. (JTCVS Open 2021;7:274-85)

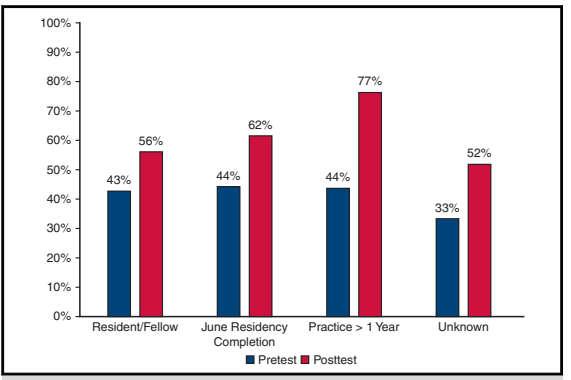

Participant scores improved across all content areas.

CENTRAL MESSAGE

Participation in the Core Curric-

ulum Review Course can improve

participant scores on an exam

that focuses on cardiothoracic

subject matter to prepare par-

ticipants for board certification.

\section{PERSPECTIVE}

This study shows that a formal review course combined with online materials and a structured study schedule can identify areas of knowledge deficiency for focused learning. These data could be useful for residency programs and the board for improving residency education.

See Commentaries on pages 286 and 287 .
From the a Division of Cardiovascular and Thoracic Surgery, Intermountain Heart Institute, Intermountain Healthcare, Murray, Utah and 'Planning and Insights, Marketing and Communications, Intermountain Healthcare, Salt Lake City, Utah. Read at the 45th Annual Meeting of the Western Thoracic Surgical Association, Olympic Valley, California, June 26-29, 2019.

Received for publication July 19, 2019; accepted for publication July 8, 2021; available ahead of print Sept 3, 2021.

Address for reprints: John R. Doty, MD, Division of Cardiovascular and Thoracic Surgery, Eccles Outpatient Center, Intermountain Medical Center, Suite 600, 5169 S Cottonwood St, Murray, UT 84107 (E-mail: john.doty@imail.org). 2666-2736

Copyright (c) 2021 The Authors. Published by Elsevier Inc. on behalf of The American Association for Thoracic Surgery. This is an open access article under the CC BY-NCND license (http://creativecommons.org/licenses/by-nc-nd/4.0/).

https://doi.org/10.1016/j.xjon.2021.07.003
Video clip is available online.

The need for structured education during surgical training was recognized at the organization of the first residency programs, underscoring the importance of formalized acquisition of medical knowledge. ${ }^{1}$ As the scientific field expanded, more attention was paid to establishing national curricula and tools for both faculty and residents to address knowledge gaps during training. ${ }^{2-5}$ After completion of residency, however, surgeons are typically responsible for their own individual

To view the AATS Annual Meeting Webcast, see the URL next to the webcast thumbnail. 


\section{Abbreviation and Acronym \\ ABTS $=$ American Board of Thoracic Surgery}

education and preparation to meet the educational standards set by national societies and certifying boards.

The Core Curriculum Review Course in Cardiovascular and Thoracic Surgery was instituted in 1992 as part of a concerted effort to improve knowledge for individuals seeking to pass the American Board of Thoracic Surgery (ABTS) qualifying examination. The course is held over a 4-day period in Salt Lake City, Utah and consists of a series of condensed, didactic lectures that cover the fundamental "core" concepts in the field. Each lecture has associated interactive questions and a printed syllabus to help participants identify those areas needing more focused study. The materials are then captured in a digital format and hosted in a Web-based mobile application that is accessible on demand for additional review. Finally, daily text message reminders are sent to each participant to encourage adherence to a regular study schedule over the ensuing weeks before the ABTS examination.

We sought to evaluate whether attendance at the Core Curriculum Review Course with its accompanying online materials could improve participants' overall fund of knowledge and therefore assist in preparation for the ABTS qualifying examination. We assessed core knowledge before and after participation in the review course by utilizing a pretest and posttest consisting of multiple choice questions directly linked to each lecture topic.

\section{METHODS \\ Participants}

A total of 65 participants attended the Core Curriculum Review Course in 2018. Of these attendees, 29 completed both the pretest administered prior before the start of the lectures and the posttest administered 50 days after the conclusion of the course. Of these participants, $18 \mathrm{had}$ completed their residency in June 2018, 3 were fellows, 1 was a resident, and 3 had been practicing surgeons for over a year; 4 participants did not disclose their level of experience. Participants were not randomly assigned to control and "treatment" groups given the retroactive, quasi-experimental nature of the analysis. The Institutional Review Board of Intermountain Healthcare considered the study to be exempt.

\section{Instrument and Design}

At the beginning of the Core Curriculum Review Course and before any lectures, participants were instructed to complete a pretest consisting of 77 multiple choice questions to establish their baseline understanding. Each question was directly correlated with an associated topic in cardiovascular and thoracic surgery under 7 general content areas: acquired cardiac disease, cardiovascular disease, congenital heart disease, esophageal disease, heart failure/transplantation, pulmonary disease, and mediastinal disease. The test is compiled and administered within a Web-based testing application designed specifically for the course by a third-party vendor. Course attendees were not required to participate in the pretest, and attendance at each lecture was not mandatory.
During the next several weeks, participants were encouraged to adhere to a regular study schedule using the written syllabus, the online recorded lecture materials, and their own individual notes from course attendance. In addition, daily text notifications were sent to each participant's mobile phone as reminders to study a particular topic. Completion of a focused study and review was solely at the discretion of each individual and was not mandatory.

At 7 weeks after the educational review course, participants received an email prompting them to complete a posttest consisting of 77 multiple choice questions to assess their current level of understanding. As with the pretest, each question was directly correlated with one of the lecture topics and were designed to be similar, but not identical, to the questions included in the pretest. Again, participation in the posttest was not mandatory.

\section{Analysis}

The data were compiled in Excel (Microsoft, Redmond, Wash) to generate descriptive statistics for participant information as well as for item responses. SPSS Version 26 (IBM, Armonk, NY) was used to create histograms and Q-Q plots as a visual check for normality of data. SPSS was also used to assess test retest reliability. Owing to the presence of nonnormal data, a Wilcoxon signed-rank test was also performed in SPSS.

\section{RESULTS}

\section{Response Rates}

Of the 65 individuals who took part in the Core program, 59 completed the pretest, for a completion rate of $91 \%$. The overall completion rate for the posttest was $48 \%$. For the purpose of this study, only data from those who completed both the pretest and posttest were considered. These 29 participants represented a completion rate of $45 \%$ for both the pretest and posttest.

\section{Descriptive Statistics}

Although performance on the pretest and posttest individually was not a focus of this study, descriptive statistics for the overall item responses for both the pretest and posttest are provided in Table 1. These data point to the relative difficulty of the exams, with participants scoring poorly on the pretest (mean $\pm \mathrm{SD}, 47 \pm 13 \%$ ). Scores on the pretest were nonnormally distributed, with a skewness of 1.51 (standard error [SE], 0.43) and kurtosis of 6.93 (SE, 0.85 ). Scores on the posttest were higher (mean, $62 \pm 13 \%$ ) and were also nonnormally distributed (but not to the same degree as with the pretest data), with a skewness of 0.64 (SE, 0.43 ) and kurtosis of -0.11 (SE, 0.85). Q-Q plots, shown in Figures 1 and 2, provided a visual check to confirm the issues of nonnormality and the presence of outliers and to support the decision to use a nonparametric test to assess the differences between the pretest data and posttest data.

\section{Content Validity and Reliability}

Content validity was established in the development and refinement of the exam questions by the planning committee members. Each physician member of the planning committee is a currently practicing ABTS-certified cardiovascular and thoracic surgeon. All 77 questions in the respective exams are linked to a corresponding topic 
TABLE 1. Descriptive statistics for item responses in the 29 participants who completed both the pretest and posttest

\begin{tabular}{|c|c|c|c|c|c|c|c|c|}
\hline \multirow[b]{2}{*}{ Variable } & \multicolumn{2}{|c|}{ Number correct } & \multicolumn{2}{|c|}{ Number incorrect } & \multicolumn{2}{|c|}{$\%$ correct } & \multicolumn{2}{|c|}{$\%$ incorrect } \\
\hline & Pretest & Posttest & Pretest & Posttest & Pretest & Posttest & Pretest & Posttest \\
\hline Minimum & 14 & 30 & 1 & 7 & 18 & 39 & 3 & 10 \\
\hline Maximum & 75 & 69 & 55 & 47 & 97 & 90 & 82 & 61 \\
\hline Average & 36 & 48 & 39 & 29 & 47 & 62 & 53 & 38 \\
\hline Median & 36 & 47 & 41 & 30 & 47 & 61 & 53 & 39 \\
\hline SD & 9.97 & 10.02 & 9.52 & 10.08 & 13 & 13 & 13 & 13 \\
\hline
\end{tabular}

(acquired cardiac disease, cardiovascular disease, congenital heart disease, esophageal disease, heart failure/ transplantation, pulmonary disease, and mediastinal disease), with multiple questions per topic.

Because the content was the same in the pretest and posttest same, the present study focused on the sample of participants who completed both the pretest and posttest, which allowed for the use of the Pearson correlation coefficient as a measure of test-retest reliability. There was a marginal, positive correlation between the pretest and posttest that was not statistically significant $[r(27)=0.33 ; P=.80]$.

\section{Nonparametric Statistic}

Both pretest and posttest data were skewed and kurtotic, which pointed to issues of normality. To account for nonnormality, Wilcoxon signed-rank test was used. Results indicated a statistically significant difference between pretest scores (median, 47\%) and posttest scores (median, $61 \%)(z=-4.36 ; P=.00)$.

The test-retest reliability correlation was undeniably low $(r=0.33)$, with the small sample size as a likely contributing factor. Another factor could be the effect of bias or practice. With the items on the tests being identical for both the pretest and posttest, the increase in test scores between the pretest and posttest could be attributed to participants being more familiar with the exam materials.

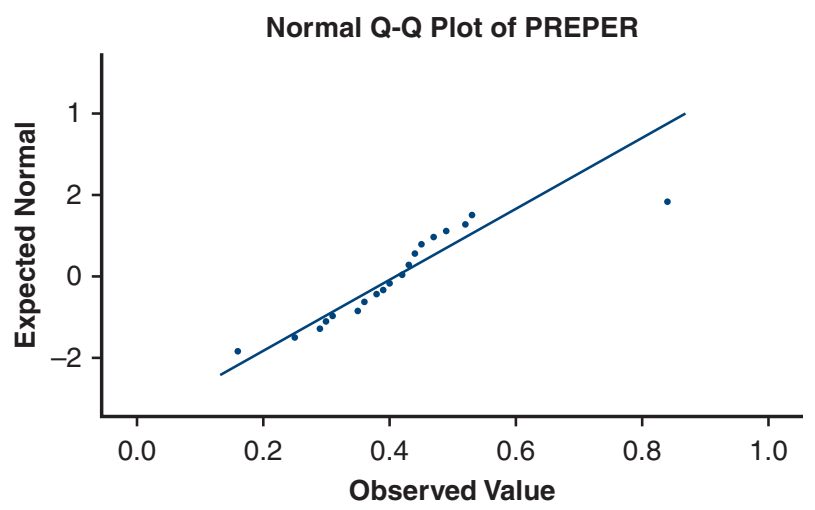

FIGURE 1. Q-Q plot for pretest. The presence of nonnormal data and outliers in the dataset supports the use of a nonparametric test to assess differences between the pretest and posttest data. PREPER, Pretest performance.
Because the data were not normally distributed and the effective sample size was small, the Wilcoxon signedrank test was used to assess for a difference in the location of the center of the data (the median) between the pretest and posttest scores. A statistically significant test statistic was obtained, supporting the idea of a meaningful change in median scores that was not due to chance alone. In terms of null hypothesis testing, the null hypothesis that there were no changes to the median between the pretest and posttest can be rejected.

\section{Individual Content Area and Topic Analysis}

The small sample size limited our ability to provide meaningful statistical comparisons between the different content areas; nonetheless, the differences in raw mean percentage scores from pretest to posttest for those who completed both tests indicated improvement in all content areas. Esophageal disease saw the greatest improvement (percent difference, $29 \%$ ), and congenital heart disease saw the least improvement (percent difference, 13\%). Mean score improvements in the remaining content areas are shown in Figure 3.

In-depth analysis of specific content topics indicated poor baseline knowledge in 16 topics, with $20 \%$ or less of participants answering the associated questions correctly on the pretest. For 6 topics, mean percentage scores were $<10 \%$ : developmental anatomy $(5 \%)$, cardiac transplantation $(7 \%)$, thoracic trauma $(8 \%)$, atrioventricular septal defect

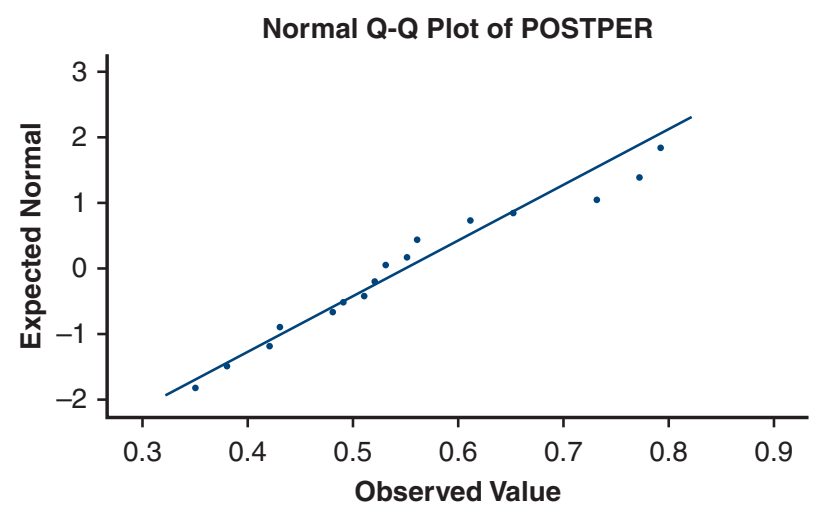

FIGURE 2. Q-Q plot for posttest. There are no outliers in this dataset, but there are nonnormal data, supporting the use of a nonparametric test to assess the differences between the pretest and posttest data. POSTPER, Posttest performance. 


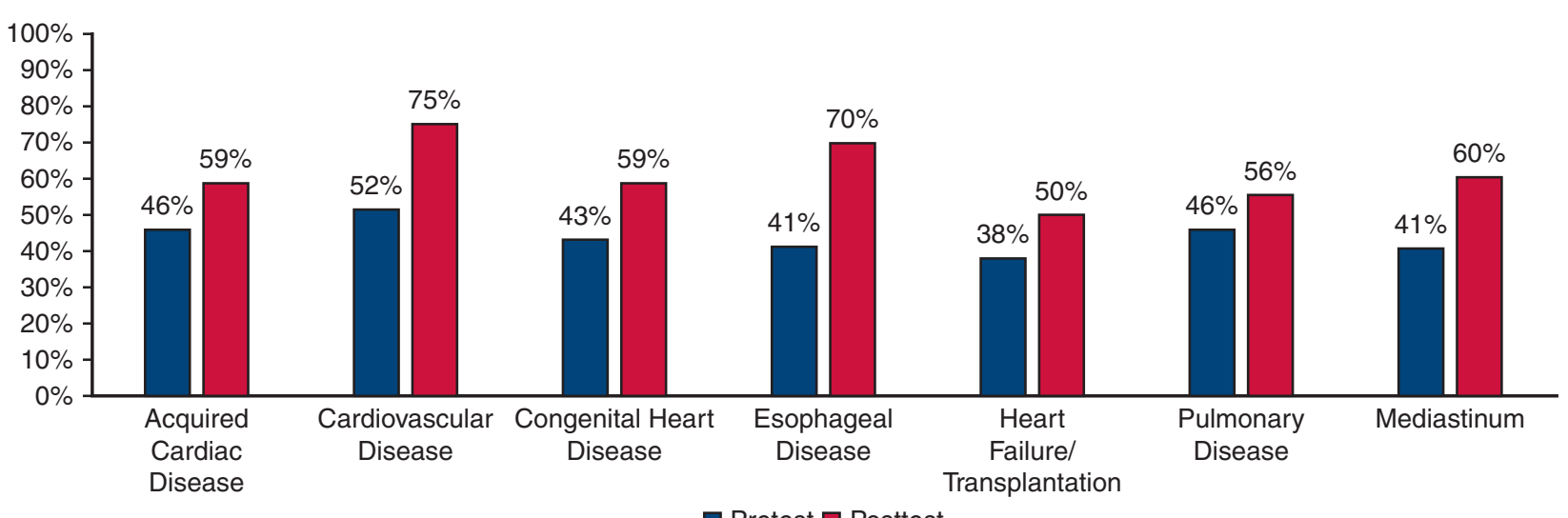

FIGURE 3. Comparison of pretest and posttest scores by subject category. All categories demonstrate improvement in posttest scores, with the most marked improvements seen in the cardiovascular disease and esophageal disease categories.

$(8 \%)$, and combined coronary/carotid/valvular disease $(10 \%)$. Results for each individual topic are provided in Appendix 1.

\section{DISCUSSION}

This study demonstrates that a focused review course in cardiovascular and thoracic surgery can improve test score performance from pretest to posttest. Figure 4 is a graphical abstract representing the methods, key results, and implications of this analysis. The quasi-experimental design precluded the ability to randomly assign participants to a treatment and control group and ultimately limited our ability to assign causation. Nonetheless, we can conclude with some level of certainty that the series of lectures and study of the printed and online review materials likely resulted in the $14 \%$ increase in median scores for the participants who completed both the pretest and posttest.
Although the combination of variables certainly was a cause, it probably was not the sole cause owing to other external factors, such as the use of accompanying online materials or practical experience in the field (Video 1).

One important limitation of this study is the small sample size inherent to this particular educational activity. A select number of individuals are preparing for the ABTS examination each year, and it will take many years to obtain large datasets for more accurate analysis. In addition, participation in the pretest and posttest is voluntary, and only roughly one-half of the course attendees completed the posttest, further reducing the dataset. One solution would be to initiate mandatory participation in both tests similar to residency in-training examinations.

A second limitation is the inability to establish a causal relationship between course attendance and test performance. Participation and engagement in the

\section{CORE Curriculum Review Course}

Methods

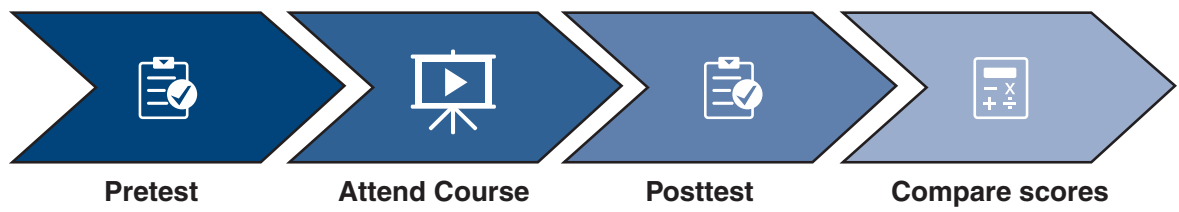

Results

$$
\begin{aligned}
& \text { - Median pretest score }=47 \% \\
& \text { - Median posttest score }=61 \% \\
& \text { - } 14 \% \text { improvement in posttest } \\
& \text { score }(P<.05) \\
& \text { - Majority of participants ( } 86 \%) \\
& \text { improved their posttest score }
\end{aligned}
$$

Implications

- Participation in a board review
course can improve standardized
test scores and improve overall
fund of knowledge
- Certain areas need additional
focus during residency training

Vy/ Intermountain
Healthcare

FIGURE 4. Methods, results, and implications of the study. Methods include administration of the pretest, attendance at the review course, administration of the posttest, and score analysis. Key results are an overall 14\% improvement in mean score, a statistically significant change. Implications are that attendance at the review course increases the overall fund of knowledge, improves standardized test scores, and can help identify areas of focus for residency training programs. 


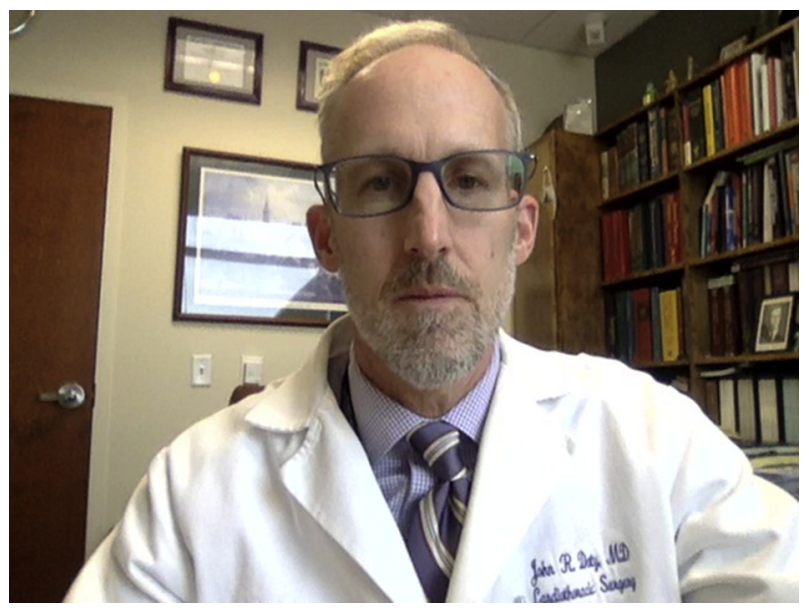

VIDEO 1. Summary of study findings. Video available at: https://www. jtcvs.org/article/S2666-2736(21)00180-7/fulltext.

individual lectures and online materials are voluntary. Selfstudy habits vary widely, and individuals may use other sources for additional review. Other studies have shown that a regular study schedule and practice examinations during residency can improve in-training examination score and national board pass rates, and even relatively short periods of intense study can result in improved test scores. ${ }^{6-9}$ Web-based learning has been shown to have a positive effect in medical education and has been adopted by the thoracic surgery community. ${ }^{10,11}$ These self-directed online curricula demonstrate improvement for in-training examination scores and allow residents to structure their own individual study methods. ${ }^{12}$ Although it is difficult to separate performance improvement due to the review course versus self-study afterward, a positive effect from the review course is supported from these data given the limited time that the majority of these particular participants have for study and preparation.

Two important issues are raised from this analysis, both of which revolve around the central concept of improving resident education. First, although the study data show improvement between 2 separate assessments, whether a similar outcome can be shown for participant performance on the ABTS qualifying examination is unknown. Passing this exam is the ultimate goal of the review course, but this would require a larger effort and cooperation to analyze outcomes from the board.

Second, specific content analysis revealed an overall paucity of core knowledge among the participants, as evidenced by the mean pretest score of $47 \%$. Particularly worrisome are the several content areas with mean scores $<20 \%$, suggesting a lack of fundamental education in these topics. These findings represent an important opportunity to focus teaching efforts not only at the review course and online materials, but also during residency training. These data could be useful to individual residency programs for refining their curricula.

\section{Conflict of Interest Statement}

The authors reported no conflicts of interest.

The Journal policy requires editors and reviewers to disclose conflicts of interest and to decline handling or reviewing manuscripts for which they may have a conflict of interest. The editors and reviewers of this article have no conflicts of interest.

\section{References}

1. Halsted WS. Training of the surgeon. Bull Johns Hopkins Hosp. 1904;15:267-75.

2. Kron IL. Challenges for training thoracic surgeons in the future. Ann Thorac Surg. 1997;63:309-11.

3. Baumgartner WA. Retooling thoracic surgery education for the 21 st century. Ann Thorac Surg. 1998;65:13-6.

4. Wilcox BR, Stritter FT, Anderson RP, Gay WA Jr, Kaiser GC, Orringer MB, et al. Systematic survey of opinion regarding the thoracic surgery residency. Ann Thorac Surg. 1993;55:1296-302.

5. Wilcox BR, Stritter FT. Curriculum change for graduate education in thoracic surgery. Ann Thorac Surg. 1993;55:1332-6.

6. de Virgilio C, Stabile BE, Lewis RJ, Brayack C. Significantly improved American Board of Surgery in-training examination scores associated with weekly assigned reading and preparatory examinations. Arch Surg. 2003;138: 1195-7.

7. de Virgilio C, Chant T, Kaji A, Miller K. Weekly assigned reading and examinations during residency, ABSITE performance, and improved pass rates on the American Board of Surgery examinations. J Surg Educ. 2008;65:499-503.

8. Ahmed A, Abid MA, Bhatti NI. Balancing standardized testing with personalized training in surgery. Adv Med Educ Pract. 2016;8:25-9.

9. Luc JGY, Verrier ED, Allen MS, Aloia L, Baker C, Fann JI, et al. Does cramming work? Impact of national web-based thoracic surgery curriculum login frequency on thoracic surgery in-training exam performance. J Thorac Cardiovasc Surg. 2018;156:922-7.

10. Gold JP, Begg WB, Fullerton DA, Mathisen DJ, Orringer MB, Verrier ED. Evaluation of web-based learning tools: lessons learned from the Thoracic Surgery Directors Association curriculum project three-year experience. Ann Thorac Surg. 2005;80:802-9; discussion 809-10.

11. Wutoh R, Boren SA, Balas EA. eLearning: a review of Internet-based continuing medical education. J Contin Educ Health Prof. 2004;24:20-30.

12. Antonoff MB, Verrier ED, Allen MS, Aloia L, Baker C, Fann JI, et al. Impact of Moodle-based online curriculum on thoracic surgery in-training examination scores. Ann Thorac Surg. 2016;102:1381-6.

Key Words: education, residency, training

\section{Discussion}

Dr Michael Smith. Our final paper is "Impact of a Focused Review Course in Cardiovascular and Thoracic Surgery on Standardized Test Performance". It will be presented by Dr Don Doty from the University of Utah.

Dr Lee McCann. We thank the Society for the privilege of the podium today. I am presenting in place of Dr Doty. I am actually the course codirector for the core review.

These are our disclosures. The review course began because of an unacceptable failure rate in the ABTS exam 
among residents at the University of Utah training program. As a result of this, a curriculum of lectures was developed by Dr Donald Doty, and the material was taken from existing textbooks such as Kirkland, Sabiston, Shields, and the Glen text. These lectures were then adapted over intervening years into a national review course that was initiated in 1992. We are now in our 25th year, and I should note that the course is also offered internationally in London each May.

The current review course consists of 77 lectures that are delivered over a 4-day period early in September. Each lecture, of course, is highly condensed but the scope is comprehensive, including adult cardiac, thoracic, and congenital. During the course, there are interactive questions and also a printed syllabus to help attendees identify the specific areas that they need more work on. All materials are also captured in a digital format and then made available in a Web-based application for future study. It is unknown whether review courses can actually impact performance on an ABTS-certifying exam. We sought to evaluate how attendance at our course could affect attendees' overall fund of knowledge and to see if a comprehensive review course could improve performance on a standardized test.

At the beginning of our course, a standardized electronic multiple choice test was administered. This consists of 77 questions, each directed to a specific lecture topic. Seventy-seven lectures were then delivered in real time over the 4 days, and then participation in the pretest along with attendance was voluntary. Participants were then encouraged over the next few weeks to adhere to a regular study schedule utilizing the printed syllabus and also the online materials that they had access to. Daily text messages were sent to each attendee reminding them about a particular study topic. Focused study and review was solely at the discretion of each participant. Then at 7 weeks after the review course, an email was sent to all participants with instructions to complete the posttest. This again was 77 standardized multiple choice questions utilizing the same electronic format, and each question again directly correlated to one specific lecture topic. Participation again was voluntary.

In the participant group, 65 provided basic demographic information. We found that 21 identified as current residents, 30 had completed training within the previous 3 months, 3 had been in practice for longer than 1 year, and 11 provided no information. On the pretest, 62 participants completed the entire exam, and the mean pretest score was $42 \%$ correct answers. The highest mean score was for cardiovascular disease at $52 \%$, and the lowest mean score was for heart failure transplant at $38 \%$. In terms of the posttest, 31 participants completed the entire exam. The mean posttest score had increased to $61 \%$ correct answers, with an absolute increase of $19 \%$ on the overall mean score, and this was statistically significant by the Wilcoxon signed-rank test. The highest mean score was for cardiovascular disease at up to $75 \%$, and the lowest mean score was for heart failure transplantation at $50 \%$. Histogram analysis showed a shift for all participants toward improved scores, and no posttest score was below 35 . Here you see a mean shift from $40 \%$ to around the $60 \%$ range.

We were able in 29 participants to directly compare tests, because these 29 completed both tests. The mean score improved from $47 \%$ to $61 \%$ with an absolute $14 \%$ increase in overall mean score, which again was statistically significant. Twenty-five participants improved their posttest score. One had an identical score, and 3 participants scored lower. The mean scores improved in all 7 general content areas, with the greatest improvement in esophageal disease of nearly $30 \%$ and the least improvement in pulmonary disease at $10 \%$. These are the 7 general content areas with the pretest score in blue and the posttest in red.

On individual content analysis pretest-specific topics, we found poor baseline knowledge in 16 topics, defined as less than $20 \%$ correct answers, with 6 topics with mean scores below $10 \%$. In the posttest, mean scores improved in 64 out of the 77 topics. Five topics had mean scores improve by more than 50\%; however, 12 topics did have a decline in mean score. We analyzed this according to prior level of training and found that the mean scores improved regardless of the level of training. Interestingly, the same scores were almost identical in current residents, those who had recently completed training, and those in practice, and then in the posttest, those who had completed training improved more than those who had been in practice.

We conclude that a focused cardiovascular and thoracic surgery review course can improve a mean test performance. The nearly $20 \%$ increase in mean score implies that baseline knowledge has improved through course attendance and then the associated study. These improvements can be achieved regardless of prior level of education. We recognize that there are limitations to this study, including the small numbers, the number of annual graduates, and voluntary participation. Furthermore, it is difficult to establish a causal relationship, as self-study habits vary widely, and, of course, individuals are not restricted to just the use of our course materials over that 8 weeks. The impact of online materials on the fund of knowledge is also unknown.

I close with this picture of Dr Donald Doty as a med student at Stanford University and pay tribute to this past president of the Western Thoracic Society and an amazing surgeon and educator who passed away 2 days ago near Salt Lake City at the age of 81. I thank the Society for the privilege of presenting these data. I would be happy to take any questions.

Dr Smith. A very nice presentation. I don't think most of us were aware of that, so thank you for providing that 
information. Our condolences on the loss of such an important contributor to our specialty and the Society. Our discussant for this paper is Melita Viegas from UPMC.

Dr Melita Viegas. Hi there, thank you Dr McCann and yes, paying tribute to Dr Doty, of course, a great surgical educator. Well, thank you for providing me with the wellwritten manuscript and also thank you to the Committee for giving me the opportunity to discuss this paper. I actually wanted to convey a belated thank you because I took the course in 2012 during my cardiac surgery training and then increased my in-service score and then passed my boards without a problem from the written perspective. I know there are a couple of other people here who have taken the course too and benefited greatly, so thank you.

Your course is impressive and clearly involves a high level of commitment and dedication. Organizing those 77 lectures and keeping the content as succinct, thorough, and up-to-date is no small feat, and also keeping several mediums takes a lot of hard work. From the written material to the Web-based material and constant text reminders, clearly the program has grown and evolved even since I took it. As you mentioned, teasing out the contribution of the course to the overall posttest score increase can be difficult. That being said, the immersive and concentrated course does offer the advantage of a true protected and focused learning experience, as well as detailed materials that make studying and reviewing significantly easier, time efficient, and effective. I am sure we can all remember the rigorous nature of our cardiac surgery training, and even with the current emphasis on surgical education and didactics, it's often difficult to completely shut out ongoing clinical duties, fight sleep deprivation, and all our surgical short attention spans. So you present excellent results that put data behind the reputation of the core curriculum course. Obviously, an increase in the pretest mean of $42 \%$ to a posttest mean of $61 \%$ is commendable. Even more impressive is the increase across the majority of the subject areas, highlighting the breadth of the course and, as you said, one day being able to see the ABTS pass rate following the course would likely further validate results. I feel like I vaguely remember at the beginning of the course kind of having an idea of the success rate afterward, part of the initial presentation.

A few questions for you. Part of the success of the review is that it includes the big topics as well as the less clinically encountered topics. How do you choose those topics and keep them up to date? Second, as you mentioned, the pretest mean score of $42 \%$ is definitely on the lower side, and it's a bit eye-opening, as a majority of the participants taking the course are residents who have completed their training or are about a year out, with the board exam usually being 1 to 2 months after the course. Do you have any suggestions or ideas to help individual programs augment their current core curriculum to better ready their residents throughout training? And then, to take it a step further, do you think there is potential for collaboration with the TSDA or TSRA to increase residents' core knowledge at an earlier stage? For example, creating another or an adjunct to the current "boot camp" that the majority of the early residents attend?

Dr McCann. Thank you for those questions. The course material is updated basically annually or any time a new textbook comes out. We read the textbook and make sure that everything is updated across congenital, and we have surgeons that present in our core review who are specialists in pediatric as well as thoracic and adult and cardiac, and so that content is kept up to date in that way. Your second question was...

Dr Viegas. It was basically about trying to give suggestions to...yeah.

Dr McCann. Oh, we've toyed with this as well, and about 3 or 4 years ago, we started sending out the reminders for that a few weeks before, and most residents, I believe, were grateful for the reminder. For instance, they will get a text reminder saying "study double-outlet right ventricle lecture" and so they look that up, many of them, and so I think that the regularity and then having something that you can look at, Web-based, within 15 to 20 minutes, it's all on their cell phone, so they can look at it real time if they're going about clinical duties, so this gives them a few tools and the reminders to get this study done. You know, you have been in residency and having that scheduled time, it just doesn't happen, and so this material enables a resident to do it on the fly, which is the way we are educated. As far as the TSDA, we have not done any collaboration and haven't been asked to do anything with that.

Dr Viegas. Okay, thank you.

Dr Smith. Richard?

Dr Richard Shemin. So I have 2 questions. First, the metric you used is improvement in the test. Do you track board passage rates among the people who participate, particularly people that may have failed the boards the first time or come into the course to have a focused study to try to improve their performance? Second, most of our residents struggle, and the failure rate is highest on the oral exams, and this is a very different type of preparation as opposed to the oral examination. Can you discuss what opportunities may be part of the course to help people that are struggling on the oral presentation of information in an oral setting?

Dr McCann. Very good questions. The last question, we do spend an afternoon on strategies to take the oral board. We spend an afternoon actually doing mock exams and presenting a few case scenarios that are proctored and give participants a chance to come up and participate in a mock exam. Most of them are watching that mock exam, but we do a few hours of oral board preparation as well.

Dr Shemin. As far as the metric of actually tracking your attendees and how they do on the exam itself? 
Dr McCann. Never in the past have we asked that. We have not felt good about asking those kind of confidential issues, but in the future, since we've instituted this pre and posttest analysis, we're going to try to collect more data on this each year so that the numbers and statistical significance are improved. We are going to add a question as to whether they've passed the written and oral and try to tease that out as well. Our experience has been the same; the written has a fairly high pass rate, and the oral is where most of the residents get tripped up.

Dr Shemin. One other quick comment. When you mentioned the materials that the lectures use, many of it is textbooks. However, as you know, the American Board of Thoracic Surgery, the TSDA and others have put together over a series of years a very comprehensive curriculum that is now owned by the STS. I really think, and we have actually told residents, that the online living curriculum is where all the information to successfully pass your board examinations can be found. So I would ask your lecturers to look at that material and be sure that there aren't things that they aren't emphasizing, missing, and also the lag time to produce a textbook and the information in it, and what's available is something that is Web-based and renewable on a more frequent basis and has a lot of editorial input may really help improve the course material.

Dr McCann. I'm familiar with that program. In my experience, it is very, very difficult to navigate and cumbersome to use, and our experience with polling residents as to how they have used that program, its use is not very good.

Dr Shemin. Well, that's been improved, and we actually track utilization by programs. There's a weekly email that goes out on a topic that every resident across the country theoretically can be studying together at the same time and then they have their separate little blogs and TSRA access to each other. So I think it's a lot better than it used to be, because yes, the whole thing is to create the content and then the user interface has to be improved, and that's been done as well as answering questions. An increasing number of programs have made this a standardized part of their training curriculum.

Dr Smith. David?

Dr David. Yeah, excellent presentation, and anecdotally I have no doubt of the importance and efficacy of this review course over the last 25 years. The only thing I have is a sort of a commentary on your title and your conclusions. For instance, you say the impact of this program on standardized test performance. It really should be on "a" standardized test, because specific... and then in your conclusions, you say that this program improves standardized test performance. The reality is that you are taking a symposium or an educational didactic, you're doing a pretest based on the curriculum of that didactic, and then you're doing a posttest based on the curriculum of that didactic, so basically, you're testing the exam, the examinee, whether or not they paid attention during that specific didactic, so you're not testing standardized test performance whether it's the in-training exam or the ABTS written exam. You're testing the attendees attention to the curriculum of that specific program, am I correct on that?

Dr McCann. Yeah, point well taken. However, I will point out that it's over a 7-week period.

Dr David. Sure.

Dr McCann. And so it's not just a response to the lectures immediately, it's almost, you know, 2 months later that we're assessing this.

Dr David. Sure. But the analysis is basically determining whether or not participants are gaining some sort of insight from the curriculum and the lectures and the teaching and online; it's basically like a Kaplan or Princeton Review for SATs.

\section{Dr McCann. Yeah.}

Dr David. One thing that you may want to do to follow up on what Dr Shemin said, is perhaps take the ACGME Milestones and break those down into components separate from your curriculum and do a pretest/posttest based on your curriculum. Do you understand what I'm saying? So not only doing your pretest/posttest on this, but just something a little bit different, not related but relevant to the educational process for our trainees.

Dr McCann. Uh-huh. But that would require having the participant each year in successive years, wouldn't it?

Dr David. No. The ACGME Milestones are a goal of what a graduate fund of knowledge should be at the end of their training, whether they're a traditional independent fellow or an integrated resident.

Dr McCann. I see.

Dr Smith. I think we can fit in 2 more discussants, so Paul and then Richard.

Dr Paul. My question I think is pretty quick. My daughter, who is a junior in high school, would actually look at these scores, $42 \%$ and $61 \%$, and she would tell me, $42 \%$ is an $\mathrm{F}$ and while improvement is commendable, $61 \%$ is a D- and doesn't exactly represent mastery of the material, especially as a posttest. So I think the "ask" of Dr Shemin to track this to other standards, the board pass rates and board scores, is probably important, but also, my question is, how do you perceive this improvement?

Dr McCann. Well, people keep coming back and taking the course. I believe that there is a perceived improvement in certainly our residents and again, there's a national attendance, and so I believe there's a benefit. This was a chance and an attempt to try to quantify that, but Dr Shemin's points are well taken. I don't know how the Board would respond to attempts to correlate some of these things and get that data.

Dr Paul. The Board wants to see an educated workforce, you know, people who have been well-trained, who all 
should potentially pass. There's a lot of paranoia and concern, that's why courses are popular, people enroll and reenroll, but you are trying to provide a product that will give some promise to an attendee for the time, effort, and expense, and that they will have a better chance of passing the boards, be able to organize their knowledge better, whatever. But I think the Board will have no problem to get to...I think someone who's taken the course should be willing to let you know in feedback whether they passed their exam. I don't think the Board's going to give you that information because of confidentiality, but I think you should be able to easily get that information from the attendees.

Dr McCann. Yeah. We will try that, thanks.

Dr Smith. We have time for one more comment or question.

Dr Richard. Yeah, first, thanks, I want to thank you for giving this on obviously what was short notice, and I'm sure the Society would want to express its condolences to the Doty family. My question to you, though, is how do you define a standardized test on this? Are you...I think this is one year you did this over, and did you give the same questions pre and post, or could this just have been a simpler test the second time?

Dr McCann. No. The test was different, but very similar. Again, structured according to the same topics.

Dr Richard. But they could have been easier questions, right? Or, I mean, how do you know this is standardized in the sense that it is tested over a long period of time, that these are relevant and validated questions or are they, you know, just good questions in your guys' minds, but they could have been easier on the second, on the posttest.

Dr McCann. They could have. But we believe that the data shows differently, yeah.

Dr Smith. Well, thank you very much, that was great. So I want to conclude this Scientific Session IV for the WTSA, and I want to thank an excellent group of presenters, discussants, and audience participants—so thank you very much. 


\section{APPENDIX 1. RESULTS BY SPECIFIC CONTENT TOPIC}

\begin{tabular}{|c|c|c|c|c|c|c|c|c|c|c|c|}
\hline $\mathbf{Q}$ & Topic & $\mathbf{N}$ & FFEOOR & PRENOOR & PPETOTAL & FFE $\%$ & POSTOOR & POSTINOOR & POSTTOTAL & POST $\%$ & DFF \\
\hline 1 & $\begin{array}{l}\text { Esophageal diagnostic } \\
\text { procedures }\end{array}$ & 94 & 25 & 38 & 63 & 40 & 28.00 & 3.00 & 31.00 & 90 & 51 \\
\hline 2 & Pulmonary diagnostic testing & 94 & 33 & 30 & 63 & 52 & 20.00 & 11.00 & 31.00 & 65 & 12 \\
\hline 3 & Thoracic trauma & 93 & 5 & 57 & 62 & 8 & 14.00 & 17.00 & 31.00 & 45 & 37 \\
\hline 4 & $\begin{array}{l}\text { Bullous emphysema and } \\
\text { pneumothorax }\end{array}$ & 94 & 34 & 29 & 63 & 54 & 21.00 & 10.00 & 31.00 & 68 & 14 \\
\hline 5 & Pulmonary infections & 93 & 28 & 34 & 62 & 46 & 14.00 & 17.00 & 31.00 & 45 & 0 \\
\hline 6 & $\begin{array}{l}\text { Pulmonary fungus, } \\
\text { tuberculosis }\end{array}$ & 93 & 21 & 41 & 62 & 34 & 10.00 & 21.00 & 31.00 & 32 & -2 \\
\hline 7 & Mediastinal tumors & 93 & 8 & 54 & 62 & 13 & 14.00 & 17.00 & 31.00 & 45 & 32 \\
\hline 8 & Pulmonary anomies & 93 & 31 & 31 & 62 & 50 & 24.00 & 7.00 & 31.00 & 77 & 27 \\
\hline 9 & Lung cancer-diagnosis & 93 & 34 & 28 & 62 & 55 & 16.00 & 15.00 & 31.00 & 52 & -3 \\
\hline 10 & Lung cancer-staging & 93 & 31 & 31 & 62 & 50 & 14.00 & 17.00 & 31.00 & 45 & -5 \\
\hline 11 & Lung cancer-surgery & 93 & 15 & 47 & 62 & 24 & 23.00 & 8.00 & 31.00 & 74 & 50 \\
\hline 12 & $\begin{array}{l}\text { Lung cancer-metastatic } \\
\text { disease and adjuvant } \\
\text { therapy }\end{array}$ & 93 & 34 & 28 & 62 & 55 & 16.00 & 15.00 & 31.00 & 52 & -3 \\
\hline 13 & Benign lung tumors & 93 & 46 & 16 & 62 & 74 & 29.00 & 2.00 & 31.00 & 94 & 19 \\
\hline 14 & Thoracic outlet syndrome & 93 & 31 & 31 & 62 & 50 & 25.00 & 6.00 & 31.00 & 81 & 31 \\
\hline 15 & $\begin{array}{l}\text { SVC syndrome and } \\
\text { pulmonary embolism }\end{array}$ & 93 & 17 & 45 & 62 & 27 & 12.00 & 19.00 & 31.00 & 39 & 11 \\
\hline 16 & $\begin{array}{l}\text { Chest wall congenital } \\
\text { deformities and tumors }\end{array}$ & 93 & 23 & 39 & 62 & 37 & 10.00 & 21.00 & 31.00 & 32 & -6 \\
\hline 17 & The diaphragm & 93 & 20 & 42 & 62 & 32 & 17.00 & 14.00 & 31.00 & 55 & 23 \\
\hline 18 & The pleura & 93 & 18 & 44 & 62 & 29 & 22.00 & 9.00 & 31.00 & 71 & 42 \\
\hline 19 & The trachea & 93 & 48 & 14 & 62 & 77 & 18.00 & 13.00 & 31.00 & 58 & -19 \\
\hline 20 & $\begin{array}{l}\text { Esophageal congenital } \\
\text { disorders, burns/structure }\end{array}$ & 93 & 59 & 3 & 62 & 96 & 31.00 & 0.00 & 31.00 & 100 & 5 \\
\hline 21 & Esophageal motility disorders & 93 & 12 & 50 & 62 & 19 & 24.00 & 7.00 & 31.00 & 77 & 58 \\
\hline 22 & $\begin{array}{l}\text { Gastroesophageal reflux } \\
\text { disease and benign } \\
\text { esophageal tumors }\end{array}$ & 93 & 10 & 52 & 62 & 16 & 11.00 & 20.00 & 31.00 & 35 & 19 \\
\hline 23 & Esophageal cancer & 92 & 21 & 40 & 61 & 34 & 21.00 & 10.00 & 31.00 & 68 & 33 \\
\hline 24 & Cardiac anatomy & 92 & 33 & 28 & 61 & 54 & 25.00 & 6.00 & 31.00 & 81 & 27 \\
\hline 25 & CV physiology & 92 & 45 & 16 & 61 & 74 & 28.00 & 3.00 & 31.00 & 90 & 17 \\
\hline 26 & $\begin{array}{l}\text { CV pharmacology/ } \\
\text { coagulation }\end{array}$ & 92 & 48 & 13 & 61 & 79 & 27.00 & 4.00 & 31.00 & 87 & 8 \\
\hline 27 & Critical care physiology & 92 & 21 & 40 & 61 & 34 & 17.00 & 14.00 & 31.00 & 55 & 20 \\
\hline 28 & Acute heart failure & 92 & 45 & 16 & 61 & 74 & 23.00 & 8.00 & 31.00 & 74 & 0 \\
\hline 29 & $\begin{array}{l}\text { Cardiopulmonary bypass/ } \\
\text { myocardial protection }\end{array}$ & 92 & 25 & 36 & 61 & 41 & 22.00 & 9.00 & 31.00 & 71 & 30 \\
\hline 30 & Coronary artery disease & 92 & 13 & 48 & 61 & 21 & 28.00 & 3.00 & 31.00 & 90 & 69 \\
\hline 31 & Myocardial infarction & 92 & 22 & 39 & 61 & 36 & 17.00 & 14.00 & 31.00 & 55 & 19 \\
\hline 32 & Myocardial revascularization & 92 & 40 & 21 & 61 & 66 & 21.00 & 10.00 & 31.00 & 68 & 2 \\
\hline
\end{tabular}


APPENDIX 1. Continued

\begin{tabular}{|c|c|c|c|c|c|c|c|c|c|c|c|}
\hline $\mathbf{Q}$ & Topic & $\mathbf{N}$ & FFEOOR & PRENOOR & PPETOTAL & FFE $\%$ & POSTOOR & POSTINOOR & POSTTOTAL & POST $\%$ & DFF \\
\hline 33 & $\begin{array}{l}\text { Postinfarction ventricular } \\
\text { aneurysm and VSD }\end{array}$ & 92 & 29 & 32 & 61 & 48 & 25.00 & 6.00 & 31.00 & 81 & 33 \\
\hline 34 & Ischemic mitral disease & 92 & 49 & 12 & 61 & 80 & 30.00 & 1.00 & 31.00 & 97 & 16 \\
\hline 35 & $\begin{array}{l}\text { Combined coronary/carotid/ } \\
\text { valvular disease }\end{array}$ & 92 & 6 & 56 & 61 & 10 & 9.00 & 22.00 & 31.00 & 29 & 19 \\
\hline 36 & Aortic valve disease & 92 & 24 & 37 & 61 & 39 & 18.00 & 13.00 & 31.00 & 58 & 19 \\
\hline 37 & Mitral valve disease & 92 & 8 & 53 & 61 & 13 & 12.00 & 19.00 & 31.00 & 39 & 26 \\
\hline 38 & $\begin{array}{l}\text { Tricuspid and multiple valve } \\
\text { disease }\end{array}$ & 92 & 47 & 14 & 61 & 77 & 11.00 & 20.00 & 31.00 & 35 & -42 \\
\hline 39 & Prosthetic valve selection & 92 & 29 & 32 & 61 & 48 & 21.00 & 10.00 & 31.00 & 68 & 20 \\
\hline 40 & Endocarditis & 91 & 12 & 48 & 60 & 20 & 11.00 & 20.00 & 31.00 & 35 & 15 \\
\hline 41 & $\begin{array}{l}\text { Clinical trials in coronary } \\
\text { artery disease }\end{array}$ & 91 & 8 & 52 & 60 & 13 & 29.00 & 2.00 & 31.00 & 94 & 80 \\
\hline 42 & Thoracic radiography & 91 & 45 & 15 & 60 & 75 & 27.00 & 4.00 & 31.00 & 87 & 12 \\
\hline 43 & $\begin{array}{l}\text { Anesthesia and } \\
\text { echocardiography }\end{array}$ & 91 & 15 & 45 & 60 & 25 & 13.00 & 18.00 & 31.00 & 42 & 17 \\
\hline 44 & Cardiac tumors & 91 & 30 & 30 & 60 & 72 & 24.00 & 7.00 & 31.00 & 77 & 6 \\
\hline 45 & $\begin{array}{l}\text { Hypertrophic } \\
\text { cardiomyopathy }\end{array}$ & 91 & 30 & 30 & 60 & 50 & 22.00 & 9.00 & 31.00 & 71 & 21 \\
\hline 46 & The pericardium & 91 & 37 & 23 & 60 & 62 & 8.00 & 23.00 & 31.00 & 26 & -36 \\
\hline 47 & Cardiac transplantation & 91 & 4 & 56 & 60 & 7 & 4.00 & 27.00 & 31.00 & 13 & 6 \\
\hline 48 & $\begin{array}{l}\text { Lung and heart-lung } \\
\text { transplantation }\end{array}$ & 91 & 27 & 33 & 60 & 46 & 20.00 & 11.00 & 31.00 & 66 & 20 \\
\hline 49 & Transplant immunology & 91 & 51 & 9 & 60 & 85 & 28.00 & 3.00 & 31.00 & 90 & 5 \\
\hline 50 & Assisted circulation & 91 & 9 & 51 & 60 & 15 & 10.00 & 21.00 & 31.00 & 32 & 17 \\
\hline 51 & $\begin{array}{l}\text { Surgical treatment of heart } \\
\text { failure }\end{array}$ & 91 & 35 & 25 & 60 & 58 & 3.00 & 28.00 & 31.00 & 10 & -49 \\
\hline 52 & Cardiac arrhythmias & 91 & 28 & 32 & 60 & 47 & 29.00 & 2.00 & 31.00 & 94 & 47 \\
\hline 53 & Aortic aneurysm & 91 & 15 & 45 & 60 & 25 & 13.00 & 18.00 & 31.00 & 42 & 17 \\
\hline 54 & Aortic dissection & 91 & 37 & 23 & 60 & 62 & 26.00 & 5.00 & 31.00 & 84 & 22 \\
\hline 55 & $\begin{array}{l}\text { Complications and less } \\
\text { invasive operations }\end{array}$ & 91 & 45 & 15 & 60 & 75 & 26.00 & 5.00 & 31.00 & 84 & 9 \\
\hline 56 & Developmental anatomy & 91 & 3 & 57 & 60 & 5 & 6.00 & 25.00 & 31.00 & 19 & 14 \\
\hline 57 & Palliative operations & 91 & 25 & 35 & 60 & 42 & 16.00 & 15.00 & 31.00 & 52 & 10 \\
\hline 58 & $\begin{array}{l}\text { Patent ductus arteriosus and } \\
\text { aortopulmonary window }\end{array}$ & 91 & 20 & 40 & 60 & 33 & 11.00 & 20.00 & 31.00 & 35 & 2 \\
\hline 59 & $\begin{array}{r}\text { Coarctation of the aorta- } \\
\text { interrupted aortic arch }\end{array}$ & 91 & 26 & 34 & 60 & 43 & 26.00 & 5.00 & 31.00 & 84 & 41 \\
\hline 60 & $\begin{array}{l}\text { Atrial septal defect and partial } \\
\text { anomalous venous } \\
\text { connection }\end{array}$ & 91 & 7 & 53 & 60 & 12 & 9.00 & 22.00 & 31.00 & 29 & 17 \\
\hline 61 & Ventricular septal defect & 91 & 34 & 26 & 60 & 57 & 18.00 & 13.00 & 31.00 & 58 & 1 \\
\hline 62 & Atrioventricular septal defect & 91 & 5 & 55 & 60 & 8 & 22.00 & 9.00 & 31.00 & 71 & 63 \\
\hline 63 & Tetralogy of Fallot & 91 & 30 & 30 & 60 & 50 & 10.00 & 21.00 & 31.00 & 32 & -18 \\
\hline 64 & Coronary anomalies & 91 & 15 & 45 & 60 & 25 & 14.00 & 17.00 & 31.00 & 40 & 20 \\
\hline 65 & Truncus arteriosus & 91 & 37 & 23 & 60 & 62 & 27.00 & 4.00 & 31.00 & 87 & 25 \\
\hline
\end{tabular}


APPENDIX 1. Continued

\begin{tabular}{|c|c|c|c|c|c|c|c|c|c|c|c|}
\hline $\mathbf{Q}$ & Topic & $\mathbf{N}$ & FFEOOR & PRENOOR & PPETOTAL & FFE $\%$ & POSTOOR & POSTINOOR & POSTTOTAL & POST $\%$ & DFF \\
\hline 66 & $\begin{array}{l}\text { Pulmonary stenosis- } \\
\text { pulmonary atresia }\end{array}$ & 90 & 40 & 19 & 59 & 68 & 29.00 & 2.00 & 31.00 & 94 & 26 \\
\hline 67 & Vascular rings and sling & 90 & 22 & 37 & 59 & 37 & 9.00 & 22.00 & 31.00 & 29 & -8 \\
\hline 68 & Congenital aortic stenosis & 90 & 26 & 33 & 59 & 44 & 21.00 & 10.00 & 31.00 & 68 & 24 \\
\hline 69 & $\begin{array}{l}\text { Sinus of Valsava aneurysm/ } \\
\text { fistula }\end{array}$ & 90 & 47 & 12 & 59 & 80 & 28.00 & 3.00 & 31.00 & 90 & 11 \\
\hline 70 & Ebstein anomaly & 90 & 20 & 39 & 59 & 34 & 15.00 & 16.00 & 31.00 & 48 & 14 \\
\hline 71 & Single ventricle anomalies & 90 & 40 & 19 & 59 & 68 & 28.00 & 3.00 & 31.00 & 90 & 23 \\
\hline 72 & $\begin{array}{l}\text { Hypoplastic left heart } \\
\text { syndrome }\end{array}$ & 90 & 44 & 15 & 59 & 75 & 2.00 & 29.00 & 31.00 & 6 & -68 \\
\hline 73 & $\begin{array}{l}\text { Transposition of the great } \\
\text { arteries }\end{array}$ & 90 & 21 & 38 & 59 & 36 & 26.00 & 5.00 & 31.00 & 84 & 48 \\
\hline 74 & Corrected TGA & 90 & 23 & 36 & 59 & 39 & 27.00 & 4.00 & 31.00 & 87 & 48 \\
\hline 75 & DORV and atrial isomerism & 90 & 8 & 51 & 59 & 14 & 9.00 & 22.00 & 31.00 & 29 & 15 \\
\hline 76 & $\begin{array}{l}\text { Total anomalous pulmonary } \\
\text { venous connection-cor } \\
\text { triatriatum }\end{array}$ & 90 & 11 & 48 & 59 & 19 & 14.00 & 17.00 & 31.00 & 45 & 27 \\
\hline 77 & $\begin{array}{l}\text { Antireflux operation in the } \\
\text { setting of gastroesophageal } \\
\text { reflux disease }\end{array}$ & 70 & 23 & 19 & 42 & 56 & 18.00 & 10.00 & 28.00 & 64 & 10 \\
\hline
\end{tabular}

